\title{
Identifying Health Facilities outside the Enterprise: Challenges and Strategies for Supporting Health Reform and Meaningful Use
}

Authors

Brian E. Dixon, MPA, PhD, FHIMSS (Corresponding Author)

Assistant Professor, School of Informatics and Computing, Indiana University

Research Scientist, Center for Biomedical Informatics, Regenstrief Institute, Inc.

Investigator in Residence, Center for Health Information and Communication, Department of Veterans Affairs, Veterans Health Administration, Health Services Research and Development Service CIN 13-416, Richard L. Roudebush VA Medical Center

410 W. 10th St, Suite 2000, Indianapolis, IN 46202, USA

bedixon@regenstrief.org

phone 317-278-0046

fax 317-274-9305

Cyril Colvard

Software Development Manager, Center for Biomedical Informatics, Regenstrief Institute, Inc.

410 W. 10th St, Suite 2000, Indianapolis, IN 46202, USA

colvardc@regenstrief.org

William M. Tierney, M.D.

President and CEO, Regenstrief Institute, Inc.

Chancellor's Professor and Sam Regenstrief Professor of Health Services Research

Associate Dean for Clinical Effectiveness Research

Indiana University School of Medicine

410 W. 10th St, Suite 2000, Indianapolis, IN 46202, USA

wtierney@iupui.edu

Keywords: Health information exchange; Computer Communication Networks; Vocabulary, Controlled; Health Facilities; Health Care Reform

This is the author's manuscript of the article published in final edited form as:

Dixon, B. E., Colvard, C., \& Tierney, W. M. (2015). Identifying health facilities outside the enterprise: challenges and strategies for supporting health reform and meaningful use. Informatics for Health and Social Care, 40(4), 319-333. http://doi.org/10.3109/17538157.2014.924949 


\section{ABSTRACT}

Objective: To support collation of data for disability determination, we sought to accurately identify facilities where care was delivered across multiple, independent hospitals and clinics.

Methods: Data from various institutions' electronic health records were merged and delivered as continuity of care documents to the United States Social Security Administration (SSA).

Results: Electronic records for nearly 8,000 disability claimants were exchanged with SSA. Due to the lack of standard nomenclature for identifying the facilities in which patients received the care documented in the electronic records, SSA could not match the information received with information provided by disability claimants. Facility identifiers were generated arbitrarily by health care systems and therefore could not be mapped to existing international standards.

Discussion: We propose strategies for improving facility identification in electronic health records to support improved tracking of a patient's care between providers to better serve clinical care delivery, disability determination, health reform, and meaningful use.

Conclusion: Accurately identifying the facilities where health care is delivered to patients is important to a number of major health reform and improvement efforts underway in many nations. A standardized nomenclature for identifying health care facilities is needed to improve tracking of care and linking of electronic health records. 
RUNNING HEAD: IDENTIFYING HEALTH FACILITIES

\section{INTRODUCTION}

\section{Health information exchange}

Health information exchange (HIE) is the electronic transfer of clinical and administrative information across diverse and often competing health care organizations (1). HIE has the potential to improve access to fragmented information while also decreasing health care costs. For example, delivering the right information to the right person at the right time using electronic exchange has the potential to reduce nearly one out of five patient safety errors and as many as $70 \%$ of preventable adverse drug events (2). Furthermore, one in four U.S. adult patients reported that their medical records or test results were not available during a scheduled visit or that medical tests were duplicated unnecessarily (3). Additional studies suggest that HIE has a net societal savings, with the potential to save billions in aggregate health care costs through reductions in unnecessary medical tests, procedures, and hospitalizations (4-6).

Given its potential to improve safety, quality and costs, national policies in the United States aim to increase the use of HIE. The Health Information Technology for Economic and Clinical Health (HITECH) provisions of the American Recovery and Reinvestment Act of 2009 authorized incentive payments to eligible professionals and hospitals that adopt and 'meaningfully use' electronic health records. In its final rule for the second stage of the meaningful use (MU) incentive program, the Centers for Medicaid and Medicare Services (CMS) elevated the need for HIE to achieve several core objectives (7). For example, eligible providers and hospitals are required to electronically transmit a summary of care record to another setting or provider of care for at least $10 \%$ of transfers or referrals. The HITECH legislation further authorized the creation of federal programs to rapidly build capacity for exchanging information across the health care system $(8,9)$. Other countries have adopted national policies to 
RUNNING HEAD: IDENTIFYING HEALTH FACILITIES

encourage HIE (10-12). All these HIE efforts require merging of patients' records across multiple care providers within and between health care systems.

In addition to incentives for local and regional HIE, the U.S. government established a nationwide health information network (13-15). The network recently evolved into the eHealth Exchange managed by Healtheway (16), a public-private partnership that seeks to connect individual HIE networks to one another as well as federal agencies such as the Veterans Administration (VA) and the Centers for Disease Control and Prevention (17-20). An example outside the U.S. is the Rwandan Health Enterprise Architecture initiative (21), which is implementing a nationwide HIE to improve maternal child health.

\section{Semantic interoperability}

A key challenge to HIE in all nations at all levels is semantic interoperability, the ability for one health information system to receive data or information from another system without prior negotiation and have data queries and business rules work reliably against the received data or information (22). To achieve semantic interoperability, all parties must use clinical data standards that provide a common framework and language for communicating shared meaning in electronic messages.

Standard vocabularies for representing clinical data exist, and the current versions of available standards are mature with significant content coverage (23). Two examples of clinical data standards include: 1) Logical Observation Identifiers Names and Codes (LOINC), which provides universal identifiers for laboratory tests and other clinical observations (24); and 2) Systematized Nomenclature of MedicineClinical Terms (SNOMED CT), which provides universal identifiers for organisms, substances, diseases, and other findings that may be recorded in the medical record or identified in test results (25).

Although standard vocabularies are mature and available for use, most hospitals, laboratories, and physician offices continue to rely on local, idiosyncratic and incompatible ways of identifying clinical 
RUNNING HEAD: IDENTIFYING HEALTH FACILITIES

observations (e.g., laboratory tests, clinical measurements) and their results. In an analysis of electronic laboratory reports from two state health departments, we found that less than 1-in-6 electronic messages included a standardized code $(26,27)$. Furthermore, the use of standardized codes was highly variable across health care organizations. A national laboratory that performed a high volume of tests for lead in blood regularly used LOINC codes, while many hospital labs never used either LOINC or SNOMED codes. We observed a strong preference for local and regional test names, which varied between the two neighboring states. Variable adoption and use of standards hampers interoperability and HIE initiatives.

Given the prevalence of proprietary codes, HIE often requires a mapping process to translate local names and identifiers into standardized vocabularies. Standards compliance and mapping enables collecting high quality data once to enable re-use. So called write once, read many (WORM) approaches are necessary in health care to support multiple downstream uses of clinical data, including quality measurement, performance improvement, population health, surveillance, policymaking, research, education, and reimbursement (28).

\section{Facility identification}

While lab tests and diagnoses have mature vocabularies associated with them, much less work has focused on standardizing other items recorded in electronic health records (EHRs) to support downstream re-use of clinical data. A prime example is the facility where care was delivered to the patient. We define facility as a concept which represents multiple dimensions of a care delivery location. Primary dimensions commonly associated with a facility include its name and geospatial location. Facilities are complex, however, and may possess many other dimensions, including one or more clinical services to denote the type of care provided (e.g., primary care, radiology, pharmacy, ambulance), organizational hierarchy to denote relationships within an integrated health system, and infrastructure 
RUNNING HEAD: IDENTIFYING HEALTH FACILITIES

to denote the capacity of the facility for providing care (e.g., running water, electricity). While there are standards for geospatial location (e.g., longitude, latitude), there is no widely accepted standard to denote whether an encounter occurred at the primary care clinic on a medical center campus or a suburban community private practice, both of which could be facilities in a single integrated delivery network.

Inconsistent or even missing facility data present a critical challenge to HIE, especially HIE services that aim to support health reform and meaningful use. The remainder of this article explores the use of nomenclature to describe the facilities where medical services are performed. We first describe the value of accurately identifying health care facilities. Next, using data from a large Midwestern statewide HIE, we discuss the inherent challenges in resolving facility data from disparate clinical information systems in use today. Finally we propose short and long-term strategies for improving facility identification.

\section{THE VALUE OF ACCURATE IDENTIFICATION OF HEALTH CARE FACILITIES} Use cases that rely on facility identification

Accurately identifying facilities is important for a range of clinical data use cases. Review of a patient's past medical history, including a list of recent lab tests, procedures, medications, and other treatments may not require the reviewing provider to know exactly where these services were delivered. However, facility identification is critical to communication and coordination across providers and the attribution of care and outcomes to specific health care providers. Health reform and meaningful use objectives aim at improving care coordination through the use of HIE and accountable care organizations (ACOs). Primary care providers often need to coordinate care among specialists that may be inside or outside their practice's integrated delivery network. For example, the VA estimates that roughly $60 \%$ of care its patients receive is provided by non-VA providers (19). Similarly, to manage risk and coordinate care, 
RUNNING HEAD: IDENTIFYING HEALTH FACILITIES

ACOs will likely need to identify and contact a number of different providers who are both within and external to the ACO. Current estimates suggest that between $40 \%$ and $67 \%$ of care will be provided by facilities outside an ACO (29).

There are also a variety of secondary uses of clinical data that rely on accurate medical facility identification. Billing, quality improvement, adverse event detection, and research require identifying facilities where services were performed. The provenance or origin where data was captured is also important for routine monitoring of population health, such as disease surveillance $(30,31)$. To deliver contextually relevant clinical decision support (CDS) alerts based on emerging public health threats, CDS systems also must accurately identify facilities including specialties and providers within those facilities $(32,33)$. Accurate facility identification further supports fraud and abuse investigations by enabling attribution of targeted activities (e.g. narcotic prescriptions or other illicit activities) to specific facilities.

\section{The determination of disability use case}

According to the U.S. Census Bureau, 18.7 percent (56.7 million) of the civilian, noninstitutionalized U.S. population reported a communicative, mental, or physical disability as of 2010 (34). The U.S. Social Security Administration (SSA) provides benefits - financial assistance and Social Security Disability Insurance (SSDI) - to disabled Americans who are not able "to engage in any substantial gainful activity by reason of any medically determinable physical or mental impairment" (35). In 2012, SSA provided benefits to 10.9 million disabled Americans and their dependents (36).

To determine disability and award benefits, the SSA uses a sequential evaluation process that considers the interaction of complicated medical, legal, and vocational concepts when reviewing applications from claimants (37). Claimants initiate the application process at one of 1,300 SSA field offices across the U.S. Field office staff guide claimants in completing a "disability claim starter kit" that contains information on the claimant's medical condition, providers, and treatments as well as the individual's past work, 
RUNNING HEAD: IDENTIFYING HEALTH FACILITIES

education and training. This information includes the names and addresses of all health care providers and facilities from which the claimants have received care for their disability and co-morbid conditions. Completed kits are then sent to a Disability Determination Services (DDS) unit operated by one of the 50 state-run social security agencies funded by the federal SSA. Disability evaluation specialists and a physician (or psychologist) review the information in the starter kit then proceed to gather additional evidence necessary to make a disability determination. This process involves a series of requests to hospitals, physician offices, mental health clinics, and other care facilities for clinical documentation relative to the claim of disability. Once sufficient information has been gathered, a decision is made and the claimant is notified in writing of the decision.

SSA spends over $\$ 500$ million each year to request and process more than 15 million medical records associated with over 3 million applications $(38,39)$. Many responses are incomplete, necessitating rerequests for additional information, and requests often go unanswered, which leads to delays that decrease access to care and increase uncompensated care costs for providers $(39,40)$. Independent assessments of SSA disability determination by researchers, the Institute of Medicine, and the Social Security Advisory Board conclude that existing, paper-based processes are outdated, inefficient and need reform $(37,41,42)$.

In 2010, in an effort to improve its cumbersome processes, the SSA contracted (43) with the Regenstrief Institute (44) to establish a process for accessing Indiana SSA disability claimants' electronic health data stored in the Indiana Network for Patient Care (INPC), a statewide HIE that currently captures detailed clinical data from more than 50 Indiana hospitals and 100 other health care facilities along with all commercial labs and imaging facilities, four large health insurers, and Indiana Medicaid $(45,46)$. The hope was that more efficient electronic processes to collate and process medical records would lead to faster and more accurate determination of disability eligibility (39). 
RUNNING HEAD: IDENTIFYING HEALTH FACILITIES

In parallel with other HIE organizations, Regenstrief developed then deployed an eHealth Exchange service in which an authorized request for medical records from SSA could be fulfilled automatically. The service was built using available standards, including the Health Level 7 (HL7) clinical document architecture (CDA), the Integrating the Healthcare Enterprise (IHE) cross-gateway exchange (XCA) profile, and vocabulary standards like LOINC and SNOMED (14). The SSA Disability Determination Office would submit a query for medical evidence for a claimant, providing sufficient information to match the request to a specific patient in the INPC. Upon making a successful match, results were delivered as a CDA-based continuity of care document (CCD). The CCD contained an electronic disability record with numeric and coded data along with text-based documents that included data on clinical encounters, problems and diagnoses, medications, laboratory and imaging test results, progress notes, and hospital discharge summaries for the claimant covering a time period specified in the query by the SSA. The CCD, once delivered to the SSA, was presented to disability claims experts in a format that they could review.

\section{THE CHALLENGE OF RECONCILING OR MAPPING FACILITY INFORMATION AND RELATIONSHIPS}

\section{Our experiences with idiosyncratic facility identifiers}

Between May 2012 and June 2013, Regenstrief delivered CCDs to SSA for 7,732 Indiana disability claimants. This represents approximately $20 \%$ of the annual volume of SSA requests for medical evidence for the state, which is the target established in the partnership agreement between SSA and Regenstrief. Although the INPC's SSA eHealth Exchange service has been a success, it uncovered an important challenge facing the expansion of HIE efforts in the U.S. and other countries. Shortly after production began, the SSA noted that the medical facility names in the CCDs from the INPC were not the same as those provided by the claimants and could not be decoded by the SSA disability reviewers. Some examples include: a cardiology service at a suburban hospital was denoted as "WKRANC"; a university hospital was denoted as "UH"; and the surgical ward at a large hospital was denoted as "B2". 
RUNNING HEAD: IDENTIFYING HEALTH FACILITIES

Regenstrief represents facility information in the <playingEntity > and <scopingEntity > tags of its CCDs to identify the source of clinical observations and text elements (Figure-1).

$<$ Insert Figure-1 approximately here>

The SSA asked Regenstrief to examine its facility names and translate them into human readable values that could be used by SSA's disability reviewers to reconcile them with facility names entered by the patient on his or her application for disability benefits. We found this to be a daunting challenge for a number of reasons. Facility data in the HIE is transmitted in HL7 transactions from various participants. The HL7 standard allows virtually any form of information to be represented in the PV1-3 (Assigned Location) segment, although the standard does stipulate that hierarchical relationships (e.g., point of care $->$ room $->$ bed $->$ facility) be defined. We identified a wide range of values in an analysis of $6,191,876$ encounter transactions stored in the HIE. Some organizations include the full name of the facility (e.g., "ABC Memorial Hospital”) while other organizations send cryptic codes representing the facility name (e.g., "UH"). Representative values and their relative proportion of encounter transactions are summarized in Table-1. Three-fifths (60.4\%) of all encounter transactions did not include any value in the PV1-3 segment; these null values predominantly came from two of the HIE's largest hospital networks.

$<$ Insert Table-1 approximately here $>$

While many small hospitals transmitted a few dozen various facility names or codes, the medium-tolarge hospital networks transmitted hundreds of unique identifiers that represented units, buildings, and campuses. One large, 20-hospital health system uses more than 9,000 unique facility identifiers, with codes for every campus, building, floor, unit, and bed within its network. None of them were easily interpretable by SSA reviewers. Only one hospital network had a translation table that enabled reviewers to translate cryptic codes into understandable names. Some hospitals used different facility 
RUNNING HEAD: IDENTIFYING HEALTH FACILITIES

codes depending on the source information system (e.g., lab, radiology, dictation) that transmitted the message to the HIE, but this practice was not standard for all hospitals. Furthermore, there was no central control over naming conventions or the use of a logical hierarchy to distinguish between campuses, units, or services. In other words, facility information is just as heterogeneous as local laboratory catalogs and concept dictionaries.

\section{Others' experiences with facility identifiers}

Following our internal investigation, we contacted other HIE partners (47) participating in the SSA pilot project accessing EHR data for disability determination to discuss their experiences working with facility information. We learned that the other partners were generally single enterprise HIEs (e.g., a single network with one or more hospitals and some clinics) that developed their own unique set of codes for identifying care locations within their enterprise. We found that no other HIEs participating in the SSA pilot attempted to reconcile disparate facilities from multiple health care enterprises. And yet, linking data wherever patients go for care is precisely what HIEs are supposed to do, so accurately identifying facilities is, or will soon be, a major ubiquitous problem.

From our experiences with the eHealth Exchange, an emerging nationwide HIE network in the United States, it is clear that facility identifiers and names are just as much a "Tower of Babel" as laboratory test codes and names were three decades ago. Such lack of semantic interoperability exists because heretofore all names and identifiers were only used internally to an enterprise, and there was little incentive to coordinate facility identification across hospital systems. Nationwide HIE and multi-system ACOs necessitate a change to how we describe the locations where care is delivered if we are to realize the full benefits that EHR systems and HIE networks offer.

\section{PROPOSED STRATEGIES FOR IMPROVING FACILITY IDENTIFICATION}


RUNNING HEAD: IDENTIFYING HEALTH FACILITIES

Based on our two decades of experience with standards development and HIE, we propose long- and short-term strategies for increasing semantic interoperability capacity for facility identification. For the long-term, the biomedical informatics community must adopt consistent approaches to identify and describe care facilities when exchanging health data. This will require creating and maintaining regional facility registries along with universal identifiers for all health care facilities. In the short-term, heterogeneous local identifiers and names will need to be mapped to enable regional data exchange to support the needs of ACOs and regional HIE. This process will inform the development of the long-term solution.

\section{A long term strategy for the adoption of standards for health care facilities}

In a perfect world, clinics, hospitals and other health facilities would use standardized, unique identifiers in all HL7 transactions similar to how physicians use unique physician identification numbers. Unique identifiers would allow receiving systems to easily link incoming observations (tests, notes, billing records, etc.) to the proper health care facilities. A standards development organization (SDO), federal funding agency (e.g. CMS), or a federal policymaking body (e.g., a Ministry of Health) could serve as the caretaker of a registry of health facilities for a governmental or geographical unit (state, province, country) that would be updated on a regular basis. We do not define the canonical standard or facility registry, but we describe the process for reaching consensus on them.

To develop and implement an international standard for facility identification, the biomedical informatics community must develop a novel approach or adapt an existing model. Currently there are at least three possible candidates: object identifiers (OIDs); national provider identifiers (NPIs), and the Health Industry Number System (HIN $\left.{ }^{\circledR}\right)$.

Object identifiers 
RUNNING HEAD: IDENTIFYING HEALTH FACILITIES

OIDs are globally unique identifiers for objects in a distributed system. Many health care networks and facilities already possess OIDs, as they are required for HL7 CDA-based HIE to identify assigning authorities. All facilities would need to register for separate OIDs, so chief medical informatics officers (CMIOs) would need to develop and implement a strategy for OID creation and maintenance since some facilities already have multiple OIDs for use in various CDA initiatives.

\section{National provider identifiers}

National provider identifiers (NPIs) were created by CMS to uniquely identify providers, but providers frequently practice at multiple medical facilities. CMS also allows health care organizations and facilities to request NPIs, so an alternative approach would be to require facilities to obtain an NPI if it did not already have one. However, many medical centers are large campuses composed of numerous and variable buildings, clinics, private offices, and other care delivery units. The NPI of a medical center can apply to multiple physical locations that vary greatly in the type(s) of care delivered (e.g. intensive, acute, rehabilitation, chronic, long-term residential). Therefore, there would have to be consensus on the level of granularity of the lowest denominator NPI.

\section{Health industry numbers}

The $\mathrm{HIN}^{\circledR}$ is a unique identifier used in electronic data interchange transactions among health care trading partners for supply chain management (48). These identifiers are maintained by the Health Industry Business Communications Council $^{\circledR}$, an accredited international SDO which uses multiple sources to identify human health care facilities and assign each a unique identifier. A database of HIN identifiers is available for licensing. Current HIN licensees are predominantly pharmaceutical companies, medical device manufacturers, and wholesalers (49). We found no evidence indicating that HIEs are using the HIN database, even though the list of licensees includes "data intermediaries." 
RUNNING HEAD: IDENTIFYING HEALTH FACILITIES

\section{Achieving consensus}

These options, in addition to others unknown to us at the time of writing this article, will need to be discussed by a collaborative of interested parties. This could be conducted via a working group within the S\&I Framework (wiki.siframework.org), Care Connectivity Consortium, Integrating the Healthcare Enterprise (IHE), or HealtheWay communities. The group will need to decide how best to identify facilities, which can be modeled as objects with a set of extensible properties, when exchanging health care data. For example, current CDA R2 specifications permit the identification of the service delivery location using three properties: code, location, and serviceProviderOrganization. Given that health care facilities can potentially have many properties, existing CDA specifications may need to be modified or extended. In the recently released Care Services Directory specification released by IHE, the extensibility of facilities was identified as an open issue to be resolved (50).

\section{A short term strategy for mapping local codes to regional identifiers}

While developing and promoting a consensus-based international standard for facility identification is a long-term solution, the standards development process is unlikely to meet the immediate need for facility identification for ACOs and HIEs. Therefore a short-term workaround is needed to create and map a small set of regional identifiers to the heterogeneous local identifiers currently transmitted in HL7 messages. This is the approach we adopted to enable SSA disability record reviewers to perform their job.

The workaround involves many-to-many relationships that map incoming HL7 message identifiers to a small set of regional network and facility identifiers. Of the thousands of identifiers present in our system, the vast majority represent units, services, beds, floors, and other branches of facilities on a medical campus. We therefore created a small set of facility identifiers for the network, campus, and building levels of the facility hierarchy as these were the identifiers of interest to the SSA and other 
RUNNING HEAD: IDENTIFYING HEALTH FACILITIES

nationwide network partners. All lower level identifiers could then be mapped to the small subset of campus and regional identifiers.

To map the lower level identifiers to the regional and campus identifiers, we employed a LOINC mapping technique pioneered by Regenstrief and subsequently used by others in the biomedical informatics community (51-56). The technique focuses on prioritizing codes that account for the highest volume of transactions within the HIE or ACO. Examining the non-null PV1-3 fields, we identified 1,654 unique values representing 2,945,285 encounters. Of these, just 166 values (10.0\%) represented 2,410,535 encounters (81.8\%).Focusing on just these terms allowed human term mappers to translate a relatively small subset of identifiers in support of the greatest number of transactions. Such utilitarian approaches help minimize resource utilization in mapping projects, which are known to be costly and time-intensive processes involving specialized resources $(57,58)$.

\section{DISCUSSION}

\section{A clear strategy for identifying facilities}

While there exist mature standards for clinical messaging, vocabularies, and identifying health care providers, there is no clear standard for identifying the facilities where providers work and health care data are generated. Given the growth of HIE over the last decade and an increasing desire to produce "report cards" (e.g. performance, quality, and safety reports) by health care facility, the biomedical informatics community has an urgent need to identify disparate facilities broadly across large areas comprised of multiple enterprise care networks. Health care reform, quality and safety enhancements, and the need to document meaningful use of EHRs are further escalating the need to identify facilities outside any one provider, network, ACO, or HIE.

To address the challenge of facility identification, the informatics community needs a clear strategy. We propose short- and long-term strategies for accurately representing health care facilities in messages 
RUNNING HEAD: IDENTIFYING HEALTH FACILITIES

exchanged across regions, states, and nations. In the short-term, HIEs and provider organizations will need to map prevalent facility identifiers to a relatively small set of identifiers that can be shared with HIE partners. In the long-term, we need to identify or create a suitable, international standard for uniquely representing health care facilities in messages exchanged between health care organizations and their partners.

\section{Managing facility identifiers using registries}

In addition to a standard for uniquely representing facilities, the biomedical informatics community will need to establish standard approaches for managing facility identifiers in registries, which serve as authoritative sources for facility information (59). ACO and HIE initiatives such as OpenHIE (ohie.org), as well as independent health care organizations, may use registries to validate message senders or list facilities for display to end users. Significant work has been done by the Facility Registry API (facilityregistry.org) to develop standards for managing and sharing facility data. IHE as well as HL7 have also put forth draft specifications for managing registries of facilities $(50,60)$. These efforts are a positive sign, yet we have much work ahead of us. Collaboratively we need to discuss, test, and refine these approaches in support of using standard facility identifiers to enable disability determination, quality measurement, public health reporting, and other important HIE use cases across networks, states, and nations. 
RUNNING HEAD: IDENTIFYING HEALTH FACILITIES

\section{Conclusions}

Confronting the problem of facility identification now will support a wide range of activities that depend on exchanging and displaying information on where care is delivered. In addition to billing, care coordination, public health, other administrative use cases such as SSA disability determination and payfor-performance, facility identifiers will support efforts such as the eHealth Exchange and OpenHIE to expand the number and scope of HIEs and the ways in which they can support improved health care delivery and accountability. 
RUNNING HEAD: IDENTIFYING HEALTH FACILITIES

\section{ACKNOWLEDGEMENTS}

The authors thank Amanda Smiley, Lincoln Carr, and Andrew Martin of the Regenstrief Institute for their help in extracting service location information from real-world clinical information systems. We also thank Lacy E. Boyd, Jr. and Masoud Hosseini, graduate students at the Indiana University School of Informatics and Computing, for their assistance with mapping and data analysis. The authors also thank the Indiana Health Information Exchange and health information exchange organizations that provided insight on their local strategies for managing service location information. Further, the authors thank Eduardo Jezierski of InSTEDD as well as Shaun Grannis and Dan Vreeman of the Regenstrief Institute for providing feedback on drafts of the manuscript.

This publication is derived from work supported under a contract with the U.S. Social Security Administration (Contract No. SS00-10-60031). The views expressed in this publication are those of the authors and do not necessarily reflect the position or policy of the Social Security Administration, Department of Veterans Affairs, or the United States government. 


\section{REFERENCES}

1. Dixon BE, Zafar A, Overhage JM. A Framework for evaluating the costs, effort, and value of nationwide health information exchange. J Am Med Inform Assoc. 2010;17(3):295-301. Epub 2010/05/06.

2. Kaelber DC, Bates DW. Health information exchange and patient safety. J Biomed Inform. 2007;40(6 Suppl):S40-5. Epub 2007/10/24.

3. Schoen C, Osborn R, Squires D, Doty M, Pierson R, Applebaum S. New 2011 survey of patients with complex care needs in eleven countries finds that care is often poorly coordinated. Health affairs (Project Hope). 2011;30(12):2437-48. Epub 2011/11/11.

4. Walker J, Pan E, Johnston D, Adler-Milstein J, Bates DW, Middleton B. The value of health care information exchange and interoperability. Health affairs (Project Hope). 2005;Suppl Web Exclusives:W5-10-W5-8. Epub 2005/01/22.

5. Frisse ME, Johnson KB, Nian H, Davison CL, Gadd CS, Unertl KM, et al. The financial impact of health information exchange on emergency department care. J Am Med Inform Assoc. 2012;19(3):32833. Epub 2011/11/08.

6. Overhage JM, Dexter PR, Perkins SM, Cordell WH, McGoff J, McGrath R, et al. A randomized, controlled trial of clinical information shared from another institution. Ann Emerg Med. 2002;39(1):1423. Epub 2002/01/10.

7. Centers for Medicare \& Medicaid Services. Medicare and Medicaid Programs; Electronic Health Record Incentive Program--Stage 2. Federal Register [Internet]. 2012 [cited 2012 August 24]. Available from: http://www.ofr.gov/OFRUpload/OFRData/2012-21050 PI.pdf.

8. U.S. Department of Health \& Human Services. HITECH Programs. [updated 01/27/2011; cited 2011 December 13]; Available from:

http://healthit.hhs.gov/portal/server.pt?open=512\&objID=1487\&parentname=CommunityPage\&parent id=58\& mode $=2 \&$ in hi userid $=11113 \&$ cached $=$ true. .

9. Office of the National Coordinator for Health Information Technology. State Health Information Exchange Cooperative Agreement Program. U.S. Department of Health \& Human Services; 2010 [updated 7/27/2010; cited 2010 September 29]; Available from: http://healthit.hhs.gov/programs/stateHIE.

10. Abraham C, Nishihara E, Akiyama M. Transforming healthcare with information technology in Japan: a review of policy, people, and progress. Int J Med Inform. 2011;80(3):157-70. Epub 2011/02/05. 
11. Kim H, Kim S. Legislation direction for implementation of health information exchange in Korea. Asia-Pacific journal of public health / Asia-Pacific Academic Consortium for Public Health. 2012;24(5):880-6. Epub 2012/10/05.

12. Jha AK, Doolan D, Grandt D, Scott T, Bates DW. The use of health information technology in seven nations. Int J Med Inform. 2008;77(12):848-54. Epub 2008/07/29.

13. Dixon BE, Miller T, Overhage JM. Assessing HIE stakeholder readiness for consumer access: lessons learned from the NHIN trial implementations. J Healthc Inf Manag. 2009;23(3):20-5. Epub 2009/08/12.

14. Kuperman GJ, Blair JS, Franck RA, Devaraj S, Low AF. Developing data content specifications for the nationwide health information network trial implementations. J Am Med Inform Assoc. 2010;17(1):6-12. Epub 2010/01/13.

15. Department of Health \& Human Services US. Nationwide Health Information Network (NwHIN). 2013 [cited 2013 Feb 21]; Available from: http://www.healthit.gov/policy-researchersimplementers/nationwide-health-information-network-nwhin.

16. Healtheway. Home. 2012 [cited 2013 Feb 6]; Available from: http://www.healthewayinc.org/.

17. Grannis SJ, Stevens K, Merriwether R. Leveraging Health Information Exchange to Support Public Health Situational Awareness: The Indiana Experience. Online Journal of Public Health Informatics [Internet]. 2010; 2(2). Available from:

http://ojphi.org/htbin/cgiwrap/bin/ojs/index.php/ojphi/article/view/3213.

18. Dobbs D, Trebatoski M, Revere D. The Northwest Public Health Information Exchange's Accomplishments in Connecting a Health Information Exchange with Public Health. Online Journal of Public Health Informatics [Internet]. 2010; 2(2). Available from: http://ojphi.org/htbin/cgiwrap/bin/ojs/index.php/ojphi/article/view/3210.

19. Bouhaddou O, Bennett J, Cromwell T, Nixon G, Teal J, Davis M, et al. The Department of Veterans Affairs, Department of Defense, and Kaiser Permanente Nationwide Health Information Network exchange in San Diego: patient selection, consent, and identity matching. AMIA Annu Symp Proc. 2011;2011:135-43. Epub 2011/12/24.

20. Bouhaddou O, Bennett J, Teal J, Pugh M, Sands M, Fontaine F, et al. Toward a virtual lifetime electronic record: the department of veterans affairs experience with the nationwide health information network. AMIA Annu Symp Proc. 2012;2012:51-60. Epub 2013/01/11.

21. Jembi Health Systems. Rwanda Health Enterprise Architecture (RHEA). 2012 [cited 2013 Feb 6]; Available from: http://www.jembi.org/project/rwanda-health-enterprise-architecture-rhea/. 
22. Dolin RH, Alschuler L. Approaching semantic interoperability in Health Level Seven. J Am Med Inform Assoc. 2011;18(1):99-103. Epub 2010/11/26.

23. Bodenreider O. Biomedical ontologies in action: role in knowledge management, data integration and decision support. Yearb Med Inform. 2008:67-79. Epub 2008/07/30.

24. McDonald CJ, Huff SM, Suico JG, Hill G, Leavelle D, Aller R, et al. LOINC, a universal standard for identifying laboratory observations: a 5-year update. Clin Chem. 2003;49(4):624-33. Epub 2003/03/26.

25. Value Proposition for SNOMED CT. International Health Terminology Standards Organization; [cited 2011 November 28]; Available from: http://www.ihtsdo.org/snomed-ct/value-proposition-forsnomed-ct/.

26. Dixon BE, Siegel JA, Oemig TV, Grannis SJ, editors. Towards Interoperability for Public Health Surveillance: Experiences from Two States. International Society for Disease Surveillance 11th Annual Conference; 2012 Dec 4-5; San Diego, CA.

27. Dixon BE, Vreeman DJ, Grannis SJ. The Long Road to Semantic Interoperability in Support of Public Health: Experiences from Two States. J Biomed Inform. 2014. Epub 03/25/2014.

28. Cusack CM, Hripcsak G, Bloomrosen M, Rosenbloom ST, Weaver CA, Wright A, et al. The future state of clinical data capture and documentation: a report from AMIA's 2011 Policy Meeting. J Am Med Inform Assoc. 2013;20(1):134-40. Epub 2012/09/11.

29. Finnell JT, Overhage JM, Grannis S. All Health Care is Not Local: An Evaluation of the Distribution of Emergency Department Care Delivered in Indiana. AMIA Annu Symp Proc. 2011;2011:409-16. Epub 2011/12/24.

30. Reeder B, Revere D, Hills RA, Baseman JG, Lober WB. Public health practice within a health information exchange: Information needs and barriers to disease surveillance. Online Journal of Public Health Informatics. 2012;4(3).

31. Dixon BE, McGowan JJ, Grannis SJ. Electronic laboratory data quality and the value of a health information exchange to support public health reporting processes. AMIA Annu Symp Proc. 2011;2011:322-30. Epub 2011/12/24.

32. Gamache R, Stevens KC, Merriwether R, Dixon BE, Grannis S. Development and Assessment of a Public Health Alert Delivered through a Community Health Information Exchange. Online Journal of Public Health Informatics [Internet]. 2010; 2(2). Available from: http://ojphi.org/htbin/cgiwrap/bin/ojs/index.php/ojphi/article/view/3214/2638. 
33. Dixon BE, Gamache RE, Grannis SJ. Towards public health decision support: a systematic review of bidirectional communication approaches. J Am Med Inform Assoc. 2013;20(3):577-83. Epub 2013/03/08.

34. Brault MW. Americans With Disabilities: 2010. Washington, DC: U.S. Department of Commerce, U.S. Census Bureau Economics and Statistics Administration; 2012 Jul P70-131.

35. Social Security Administration US. $§ 416.905$. Basic definition of disability for adults. [updated 45 FR 55621, Aug. 20, 1980, as amended at 56 FR 5553, Feb. 11, 1991; 68 FR 51164, Aug. 26, 2003; 77 FR 43495, July 25, 2012; cited 2014 April 3]; Available from: http://www.ssa.gov/OP Home/cfr20/416/4160905.htm.

36. Social Security Administration US. Fast Facts \& Figures About Social Security, 2013. Washington, DC: U.S. Social Security Administration, Office of Research Evaluation and Statistics; 2013 13-11785.

37. Social Security Advisory Board. Aspects of Disability Decision Making: Data and Materials. Washington, DC 2012 Feb [cited 2014 April 3]; Available from: http://www.ssab.gov/Publications/Disability/GPO Chartbook FINAL 06122012.pdf.

38. Social Security Administration. Social Security to Fund \$24 Million in Contracts for Electronic Medical Records. Baltimore, MD2009 [updated August 7; cited 2014 April 3]; Available from: http://www.socialsecurity.gov/pressoffice/pr/electronic-med-records-pr-alt.pdf.

39. Feldman SS, Horan TA, Drew D. Understanding the value proposition of health information exchange: the case of uncompensated care cost recovery. Health Systems. 2012;2(2):134-46.

40. Tulu B, Horan TA. The electronic disability record: purpose, parameters, and model use case. J Am Med Inform Assoc. 2009;16(1):7-13. Epub 2008/10/28.

41. Ni P, McDonough CM, Jette AM, Bogusz K, Marfeo EE, Rasch EK, et al. Development of a Computer-Adaptive Physical Function Instrument for Social Security Administration Disability Determination. Archives of Physical Medicine and Rehabilitation. 2013;94(9):1661-9.

42. Improving the Social Security Disability Decision Process. Stobo JD, McGeary M, Barnes DK, editors: The National Academies Press; 2007.

43. Social Security Administration. Social Security Awards Nearly $\$ 20$ Million in Recovery Act Contracts For Electronic Medical Records. Baltimore, MD2010 [updated February 1; cited 2010 September 29]; Available from: http://www.ssa.gov/pressoffice/pr/nhin0210-pr.htm.

44. Social Security Administration. Regenstrief: Generating Efficiencies in Healthcare. 2012 [updated 2013 Feb 15; cited 2013 Feb 21]; Available from:

http://www.socialsecurity.gov/hit/success.html\#Regenstrief. 
45. Biondich PG, Grannis SJ. The Indiana network for patient care: an integrated clinical information system informed by over thirty years of experience. J Public Health Manag Pract. 2004;Suppl:S81-6. Epub 2005/01/12.

46. McDonald CJ, Overhage JM, Barnes M, Schadow G, Blevins L, Dexter PR, et al. The Indiana network for patient care: a working local health information infrastructure. An example of a working infrastructure collaboration that links data from five health systems and hundreds of millions of entries. Health affairs (Project Hope). 2005;24(5):1214-20. Epub 2005/09/16.

47. Feldman SS, Horan TA. Collaboration in electronic medical evidence development: a case study of the Social Security Administration's MEGAHIT System. Int J Med Inform. 2011;80(8):e127-40. Epub $2011 / 02 / 22$.

48. Health Industry Business Communications Council. The Health Industry Number System. 2012 [cited 2013 Feb 22]; Available from: http://www.hibcc.org/hin-system/.

49. Health Industry Business Communications Council. Health Industry Number System (HIN ${ }^{\circledR}$ ) Authorized Licensees. 2013 [updated 01-24-2013; cited 2013 Feb 22]; Available from: http://www.hibcc.org/wp-content/uploads/2012/09/Current-HIN-Authorized-Licensees.pdf.

50. Integrating the Healthcare Enterprise. IHE IT Infrastructure Technical Framework Supplement Care Services Discovery (CSD). IT Infrastructure Technical Committee; 2013.

51. Khan AN, Griffith SP, Moore C, Russell D, Rosario AC, Jr., Bertolli J. Standardizing laboratory data by mapping to LOINC. J Am Med Inform Assoc. 2006;13(3):353-5. Epub 2006/02/28.

52. Porter JP, Starmer J, King J, Frisse ME. Mapping laboratory test codes to LOINC for a regional health information exchange. AMIA Annu Symp Proc. 2007:1081. Epub 2008/08/13.

53. Regenstrief Institute, Medicine NLo. Introduction to the Guide to the Top 2000+ LOINC Laboratory Observations. 2011 [cited 2012 March 13]; Available from: http://loinc.org/resolveuid/7e7956dcb7eaa551c354ec0d37b0578c.

54. Vreeman DJ. Keeping up with changing source system terms in a local health information infrastructure: running to stand still. Studies in health technology and informatics. 2007;129(Pt 1):775-9. Epub 2007/10/04.

55. Vreeman DJ, Stark M, Tomashefski GL, Phillips DR, Dexter PR. Embracing change in a health information exchange. AMIA Annu Symp Proc. 2008:768-72. Epub 2008/11/13.

56. Gamache RE, Dixon BE, Grannis S, Vreeman DJ. Impact of selective mapping strategies on automated laboratory result notification to public health authorities. AMIA Annu Symp Proc. 2012;2012:228-36. Epub 2013/01/11. 
57. Lin MC, Vreeman DJ, McDonald CJ, Huff SM. A characterization of local LOINC mapping for laboratory tests in three large institutions. Methods of information in medicine. 2011;50(2):105-14. Epub 2010/08/21.

58. Baorto DM, Cimino JJ, Parvin CA, Kahn MG. Combining laboratory data sets from multiple institutions using the logical observation identifier names and codes (LOINC). Int J Med Inform. 1998;51(1):29-37. Epub 1998/09/28.

59. Dixon B, Grannis S. Public Health Informatics Infrastructure. In: Magnuson JA, Fu JPC, editors. Public Health Informatics and Information Systems: Springer London; 2014. p. 69-88.

60. Health Level 7. HL7 Version 3 Standard: Healthcare, Community Services and Provider Directory, Release 1. 2010. 


\section{TABLES AND FIGURES}

\section{Figure Legends}

Figure-1: Excerpt from a de-identified continuity of care document highlighting the sections where facility identification information is represented.

\section{Tables}

\begin{tabular}{|l|l|l|l|l|}
\hline $\begin{array}{l}\text { Location } \\
\text { Identifier Type }\end{array}$ & Description & Representative Values & $\begin{array}{l}\text { Number of } \\
\text { Encounters }\end{array}$ & $\begin{array}{l}\text { Percentage of } \\
\text { Encounters }\end{array}$ \\
\hline Network & $\begin{array}{l}\text { A provider network } \\
\text { or system. }\end{array}$ & WISHARD, IUH & 1576 & $0.03 \%$ \\
\hline Campus & $\begin{array}{l}\text { An individual } \\
\text { hospital or medical } \\
\text { center campus. }\end{array}$ & $\begin{array}{l}\text { WMH, MH, UH, NC, WC, } \\
\text { NORTH }\end{array}$ & $1,075,290$ & $17.37 \%$ \\
\hline Unit or Service & $\begin{array}{l}\text { The name of a } \\
\text { department or } \\
\text { other logical unit or } \\
\text { service within a } \\
\text { building; could be a } \\
\text { service in a } \\
\text { standalone building } \\
\text { (e.g., free standing } \\
\text { lab or imaging } \\
\text { unit). }\end{array}$ & $\begin{array}{l}\text { ER, B4, DERM, XRAY } \\
\text { KCAR, LAB, RAD }\end{array}$ & $1,375,947$ & $22.22 \%$ \\
\hline Blank & $\begin{array}{l}\text { No value provided. } \\
\text { NotCU, }\end{array}$ & NULL & $3,739,063$ & $60.39 \%$ \\
\hline
\end{tabular}

Table-1: Facility identification data found in INPC's HL7 messages' patient location fields 